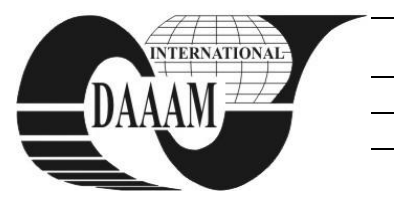

\title{
MICROHARDNESS A POSSIBLE CHARACTERISTIC OF FATIGUE DAMAGE OF METALLIC SURFACES
}

\author{
MEREUTA, V[alentin] L[ucian]; ALEXANDRU, P[etrica] \& PALAGHIAN, L[iviu]
}

\begin{abstract}
Surface finish or roughness has been recognized as being important in various engineering problems. The present study uses a microhardness tests for the characterization the influence of roughness surface finish, on the hardness variation and degradation over time in case of the plate specimens were fatigued using constant amplitude loading. The microhardness was measured at different depths and different levels of time with $100 \mathrm{~g}$ indentation loads.

Key words: surface roughness, micro hardness, damage
\end{abstract}

\section{INTRODUCTION}

In the degradation processes by fatigue, surface finish is known to have a considerable influence. The surface condition can be characterized by considering two factors: roughness surface that includes the finest (shortest wavelength) irregularities of a surface and residual stress in the surface layer.

Surface roughness should be described in terms of the nearsurface stress or strain fields caused by surface asperities performed after machining operations. This allows basic fatigue strength properties of the material to be used, along with modern theories for initiation and propagation of fatigue cracks.

The aim of this paper is to establish a relationship between microhardness and damage for improving fatigue life prediction of components with rough surfaces.

\section{THE METHODS}

\subsection{Micro hardness tests}

Vickers microhardness tests are an important tool for characterization of material properties at small scales. It has been widely used as a quantitative technique for study the mechanical behavior of materials since the early 1990s. Some material parameters can be obtained from the measured indentation curves, including tensile properties, fracture toughness, residual stress and Young's modulus (Kug et al., 2011).

The Vickers microhardness tests are use because the indentation requires minimal specimen preparation and can be performed several times on a single specimen.

The method use a hard indenter (Vickers diamond pyramid) penetrates into the specimen with a constant load. After unloading, the dimensions of the indentation in the specimen are measured and the hardness, defined as the ratio of the load applied to the projected area of the indentation and is expressed by the relation (1) (Wen et al., 2009):

$$
H_{V}=1.854\left(\frac{F}{d^{2}}\right)
$$

Where:

$\mathrm{H}_{\mathrm{V}}$-the Vickers's microhardness;

F-applied load; d-diagonal length of the impression.

The relationship between microhardness and damage was formulated by Lemaitre et al. (Lemaitre et al., 1987).
For each plastic strain magnitude, a damage value is deduced from the microhardness approach and it is computed by the relation (2) (Mkaddem et al., 2006):

$$
D_{H}=1-\frac{H_{V}}{H_{V}^{*}}
$$

Where: $H_{V}^{*}$-the microhardness law for undamaged specimen; $H_{V^{-}}$the microhardness law for fatigued specimen.

The ratio of the measured quantity $H_{V}$ to the extrapolated value $H_{V}^{*}$, gives then an indirect measure of damage $D$. This approach has been used in this study for characterizing the damage evolution for the S355JR steels specimen.

\section{EXPERIMENTAL DETAILS}

In this experiment the plate specimens on S355JR EN 10027 was grouped on three roughness levels tab.1, were fatigued using constant amplitude loading at one stress level. Samples were subjected to microhardness measurements after two hours of fatigued (T1), three hours of fatigued (T2), and four hours of fatigued (T3).

\begin{tabular}{|l|c|}
\hline Specimen & The average surface roughness \\
\hline $\mathrm{R} 1-S 355 J R$ & $\mathrm{Ra}=0.05 \div 0.1 \mu \mathrm{m}$ \\
\hline $\mathrm{R} 2-S 355 J R$ & $\mathrm{Ra}=0.2 \div 0.3 \mu \mathrm{m}$ \\
\hline $\mathrm{R} 3-$ S355JR & $\mathrm{Ra}=1.0 \div 2.0 \mu \mathrm{m}$ \\
\hline
\end{tabular}

Tab. 1. Surface roughness of the plate specimens

Vickers microhardness tests were performed at a load of $100 \mathrm{gf}$ on the polished cross-sections using a microhardness tester.

The Vickers indenter is a diamond square-based pyramid with an angle of $136^{\circ}$ between faces. The indenter was kept in contact with the surface for $10 \mathrm{~s}$ for all the loads. Three measurements were carried out at different levels of each specimen, and the average values were taken as the hardness of the specimen.

The minimum center-to-center distance between indents in all specimens was more of three times the average indentation size. Measurements were performed on the rectangular specimens of each thickness. The microhardness at $1.5,2.5$ and $3.5 \mathrm{~mm}$ depth on the cross-sections was measured. A diagonal length $\mathrm{L}$ was noted for each microhardness value corresponding to indentation load for all samples. The indentations were made across only half of each specimen's width $(5 \mathrm{~mm})$.

\begin{tabular}{|c|c|c|c|}
\hline $\begin{array}{c}\text { Depth } \\
(\mathrm{mm})\end{array}$ & $\begin{array}{c}\text { MHV R1 } \\
(\mathrm{MPa})\end{array}$ & $\begin{array}{c}\text { MHV R2 } \\
(\mathrm{MPa})\end{array}$ & $\begin{array}{c}\text { MHV R3 } \\
(\mathrm{MPa})\end{array}$ \\
\hline 1,5 & 246,569592 & 216,9198509 & 204,92136 \\
\hline 2,5 & 224,952038 & 204,2859083 & 192,79308 \\
\hline 3,5 & 211,84559 & 191,591704 & 154,95062 \\
\hline
\end{tabular}

Tab. 2. Average of microhardness for three levels of roughness 


\section{EXPERIMENTAL RESULTS AND DISCUSSION}

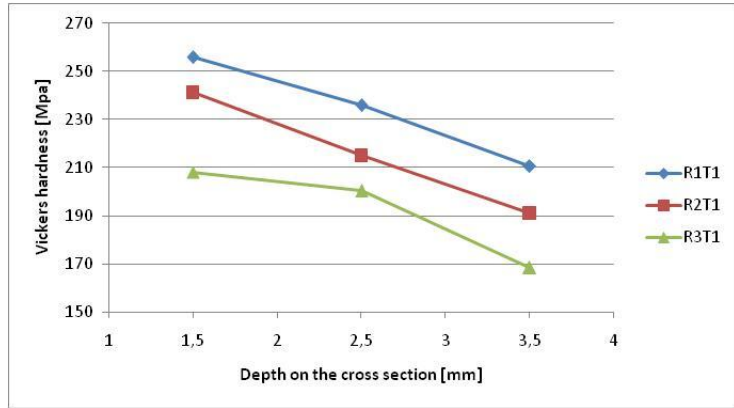

a)

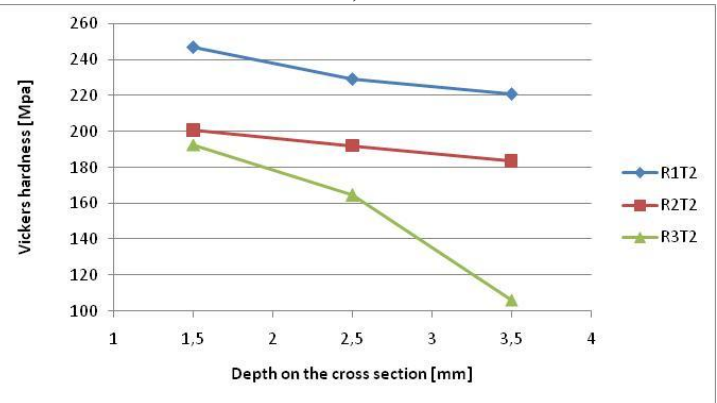

b)

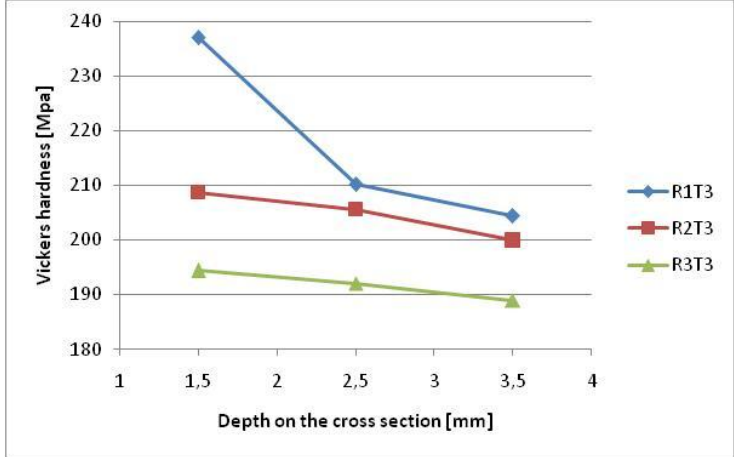

c)

Fig. 1. Dependence of Vickers microhardness of S355JR steel with measure depth: a) at $\mathrm{T} 1, \mathrm{~b}$ ) at $\mathrm{T} 2, \mathrm{c}$ ) at $\mathrm{T} 3$

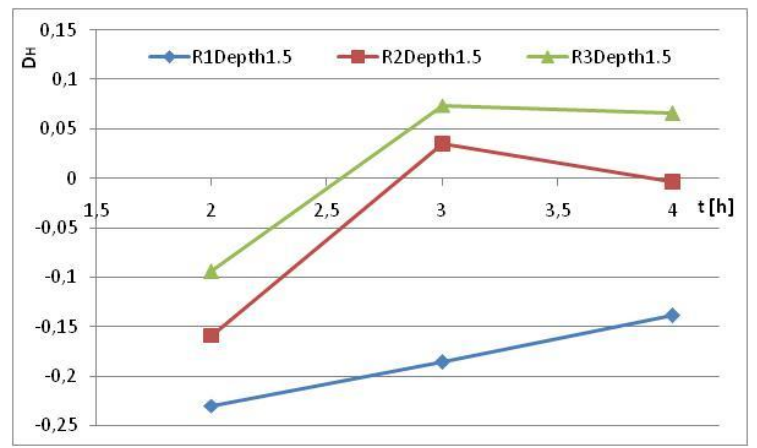

a)

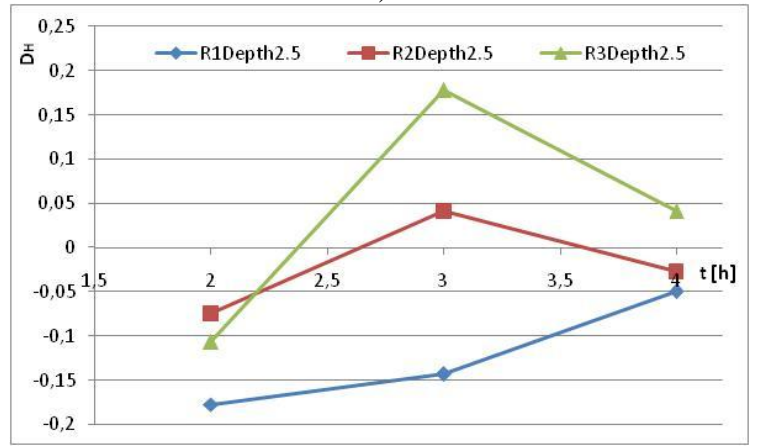

b)

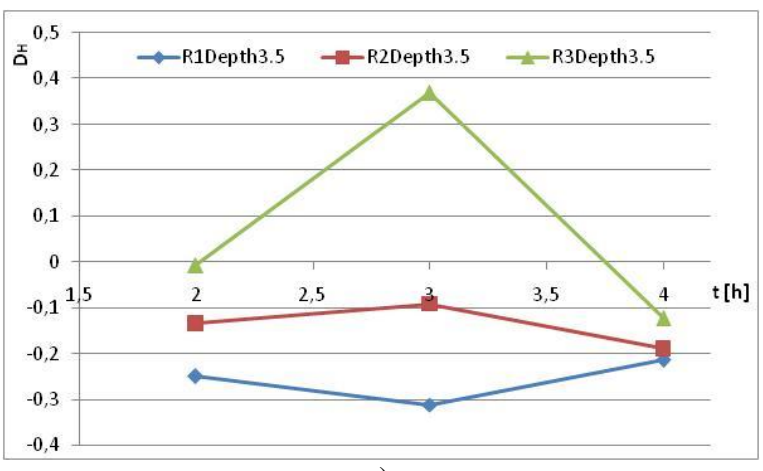

c)

Fig. 2. Dependence of Damage with time at different depth, (a) at $1.5 \mathrm{~mm}$ depth, b) at $2.5 \mathrm{~mm}$ depth, c) at $3.5 \mathrm{~mm}$ depth on the cross section) to different levels of roughness

As shown in Fig. 1, micro indentation hardness experiments of S355JR steel have shown the increase of indentation hardness with the decrease of depth. The microhardness of all the specimens varies between 192.68 and $255.95 \mathrm{Hv}$ at $1.5 \mathrm{~mm}$ depth as compared to the microhardness at $2.5 \mathrm{~mm}$ depth who varies between 164.64 and 235.73 and the microhardness at 3.5 $\mathrm{mm}$ depth who varies between 106.27 and 220.73

It is observed that the microhardness of samples with small roughness is substantially higher than microhardness of high roughness specimens. Is observed that the damage is lower in samples with the highest roughness at all levels measured and recorded lower values for samples with the lowest roughness.

\section{CONCLUSION}

Microhardness data were identified by using Vickers microhardness tests on the cross section. Curves were presented and analyzed for each specimen, and based on the results, the following conclusions were drawn:

1. Microhardness measurements may give indications for variable loads about structural changes in surface layer;

2. Can be defined a factor $d$ that varies with the duration of the load and the roughness level, that allows assessing the degree of degradation depending on the roughness level and applied load

The future paper will be The indentation size effect (ISE) using the Vickers microhardness test.

\section{REFERENCES}

Kug, H. K., Young, C. K., \& Eun, J. (2011). Evaluation of indentation tensile properties of $\mathrm{Ti}$ alloys by considering plastic constraint effect. Materials Science and Engineering A 528, 5259-5263

Lemaître, J., Dufailly, J., \& Billardon, R. (1987). Mécaniques des solides - évaluation de l'endommagement par mesure de microdureté, Académie des sciences 12, 601-604

Mkaddem, A., Gassara, F., \& Hambli, R. (2006). A new procedure using the microhardness technique for sheet material damage characterization. Journal of Materials Processing Technology 178, 111-118

Pawade, R.S., Suhas, S. J., \& Brahmankar, P.K. (2008). Effect of machining parameters and cutting edge geometry on surface integrity of high-speed turned Inconel 718, International Journal of Machine Tools \& Manufacture 48, $15-28$

Wen, W., Qi, J. W., \& Qin, W. (2009). Indentation size effect in microhardness measurements of $\mathrm{Hg} 1-x \mathrm{Mn} x \mathrm{Te}$, Trans. Nonferrous Met. Soc. China 19 s762-s766 